https://www.amerabra.org; https://fspu.uitm.edu.my/cebs; https://www.emasemasresources.com/ $5^{\text {th }}$ ABRA International Conference on Quality of Life Holiday Villa Langkawi, Langkawi Island, Malaysia, 15-16 Dec 2021

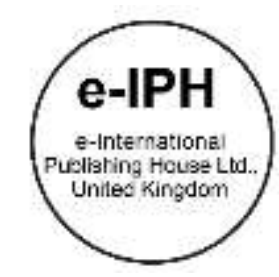

\title{
Association between Knowledge, Attitude and Practice on Gestational Diabetes Mellitus among Antenatal Women in Community Health Clinics in Selangor
}

\author{
Norazlina Md Jazli 1,2, Chong Mei Chan 1, Liao Shujuan ${ }^{3}$ \\ 1 Nursing Department, Faculty of Medicine, University of Malaya, Jalan Universiti, Wilayah Persekutuan Kuala Lumpur, Malaysia. \\ ${ }^{2}$ Centre for Nursing Studies, Health Science Faculty, Universiti Teknologi MARA, Selangor Branch, Puncak Alam Campus,Puncak \\ Alam, Selangor, Malaysia. ${ }^{3}$ West China Second University Hospital, Sichuan University, China.
}

azlinajazli@uitm.edu.my, mcchong@um.edu.my liaoshujuan2006@126.com

Tel: +60195409985

\begin{abstract}
The increasing prevalence of Gestational Diabetes Mellitus in community was an alarming public health issue. The study aim was to identify the association between knowledge, attitude, and practice of antenatal women towards GDM. Knowledge and practice were found high among respondents, representing $87.6 \%$ and $54.1 \%$. Regarding the association between knowledge, attitude, and practice, only level of knowledge had an association with the level of attitude with $p$-value 0.001 , and the study also found that, in 1 point increase in knowledge corresponds to an increase of 0.059 in practice and 1 point increase in attitude corresponds to increase 0.088 in practice.
\end{abstract}

Keywords: Knowledge; Attitude; Practice and Gestational Diabetes Mellitus

eISSN: 2398-4287@ 2021. The Authors. Published for AMER ABRA cE-Bs by e-International Publishing House, Ltd., UK. This is an open access article under the CC BYNCND license (http://creativecommons.org/licenses/by-nc-nd/4.0/). Peer-review under responsibility of AMER (Association of Malaysian Environment-Behaviour Researchers), ABRA (Association of Behavioural Researchers on Asians/Africans/Arabians) and CE-Bs (Centre for Environment-Behaviour Studies), Faculty of Architecture, Planning \& Surveying, Universiti Teknologi MARA, Malaysia.

DOI: https://doi.org/10.21834/ebpj.v6i18.3088

\subsection{Introduction}

Most married women wish to conceive soon after marriage and expect an uneventful pregnancy and labour. However, the pregnant mother is often at risk of a medical condition such as Gestational Diabetes Mellitus (GDM). The incidence of GDM in Malaysia was reported as $8.66 \%$ in 2011 and increased to $8.83 \%$ in 2012, where GDM rates were higher from pre-existing Diabetes in both years (Jeganathan \& Karalasingam,2012). Logakodie et al. (2017) had stated that in Selangor, the prevalence of GDM among new registered antenatal women was $27.9 \%$ from the total of 184 in January 2014 and slightly higher than the study before. In Gombak district, statistics from Gombak Health District by Monthly Census of Antenatal Booking \& Monthly Prevalence of GDM reported that about 1892 from 12921 registered antenatal women were diagnosed with GDM in 2017 represented $14.64 \%$. It was dramatically increased to $16.14 \%$ only from January to July 2018. This was an alarming phenomenon in public health because GDM will increase the risk to Diabetes Mellitus (DM) in later life.

Gestational Diabetes Mellitus (GDM), or Diabetes in pregnancy, is glucose intolerance with the first recognition during pregnancy (American Diabetes Association,2014). Herath, Herath \& Wickremasinghe (2017) had found that pregnant women with GDM have a higher risk of developing Type 2 Diabetes Mellitus (T2DM) in later life by tenfold. World Health Organization (WHO) (2016) estimated that about 422 million adults were living with Diabetes in 2014 compared to only 108 million in 1980. This statistic will be assumed to be increased

eISSN: 2398-4287C 2021. The Authors. Published for AMER ABRA cE-Bs by e-International Publishing House, Ltd., UK. This is an open access article under the CC BYNCND license (http://creativecommons.org/licenses/by-nc-nd/4.0/). Peer-review under responsibility of AMER (Association of Malaysian Environment-Behaviour Researchers), ABRA (Association of Behavioural Researchers on Asians/Africans/Arabians) and cE-Bs (Centre for Environment-Behaviour Studies), Faculty of Architecture, Planning \& Surveying, Universiti Teknologi MARA, Malaysia.

DOI: https://doi.org/10.21834/ebpj.v6i18.3088 
by more than 592 million in less than 25 years (International Diabetic Federations,2016) and 2030. In addition, there will be double projection deaths from the complication of T2DM (WHO,2017).

Complications from GDM affect both pregnant women and her baby, and it is reported that there is an increased rate of Caesarean section due to macrosomic babies born by GDM mothers. NOR (2012) reported that about $13.42 \%$ of cases of Caesarean in 2011 were due to GDM, and approximately $16 \%$ of babies born to GDM mothers were weighed between $4 \mathrm{~kg}$ and more. GDM also increased the risk of stillbirth wherein 2011, and data showed that about 8.05 per 1000 live births are stillbirth, and it increased to 8.27 per 1000 live birth in 2012 (NOR,2012). There are many consequences of GDM. Therefore, the study aimed to assess the association between knowledge, attitude, and practice (KAP) regarding Gestational Diabetes Mellitus among antenatal women in community health clinics in Gombak.

\subsection{Literature Review}

An individual's knowledge, attitude, and practice were normally assessed in the health science. In this study, the researcher wants to know whether a pregnant woman's increased knowledge about GDM will encourage her to change her attitude and change her behaviour to positive behaviour.

\subsection{Knowledge of Gestational Diabetes Mellitus}

Most pregnant women who had a recurrence of GDM in their pregnancy assumed that GDM only occurs during pregnancy and will be resolved once the baby has been delivered. This showed that their level of knowledge regarding GDM was low. This statement has been proved by a study of Islam et al. (2017) to 107 obese pregnant women and found that more than half of total respondents have a poor level of knowledge on GDM, representing $60.7 \%$. Similar findings were found in the study by Ogu et al. (2019) to 2595 women with reproductive age between 16 to 49 years old where the overall knowledge score for GDM was $26.2 \%$ with knowledge score about GDM and risk factors was $28.8 \%$, knowledge score for screening and treatment was $35.8 \%$ and knowledge score for complications of GDM was $30.4 \%$. Another study done by Carolan, Steele \& Margetts (2010) in exploring knowledge about gestational diabetes (GDM) among multiethnic women in Melbourne, Australia, who were receiving antenatal care in their health setting had found that statistically significant difference in the knowledge of GDM regarding the effect of GDM to baby and care needed during pregnancy with p-value 0.008 and 0.03 respectively. In contrast, a study by Hussain et al. (2015) done in one of the states in Malaysia to evaluate the knowledge about GDM and its corresponding relation with glycaemic level had found that $76.6 \%$ had adequate knowledge regarding GDM with diet values domain was the highest mean score.

\subsection{Attitude on Gestational Diabetes Mellitus}

A study by Islam et al. (2015) found that only $23.3 \%$ had a positive attitude towards GDM control and investigation. However, the respondents also expressed positive responses to the GDM education program. This finding is also similar to Carolan et al. (2010) stated that women from non-Caucasian ethnicities had low attitudes about the risk of poorer self-management of gestational diabetes. Other studies by Hussain et al. (2015) also found similar findings where only 35 participants out of 175 participants had a positive attitude towards GDM, and $73.5 \%$ of participants had adequately satisfied with the treatment and result also found that higher mean glycaemic level among patients with a negative attitude and inadequate treatment satisfaction.

\subsection{Practice on Gestational Diabetes Mellitus}

A study by Utz et al. (2017) done to health care providers regarding knowledge and practice related to GDM findings showed that public health care providers only have basic knowledge and practice related to the fundamental understanding of GDM where makes them refer cases to a specialist for management which represented $88.5 \%$. Muche, Olayemi \& Gete (2019) had found that out of 1027 pregnant women, only $33.4 \%$ have normal glucose levels and $17.6 \%$ from that among women with high physical activity levels. Yizukanji and Mwanakasale (2018) had surveyed 208 pregnant women attending antenatal clinics in Mufulira Town in Zimbabwe had found that more than half of the total respondents (56.8\%) had a fair practice score towards GDM with a mean score was $2.62 \pm 0.84$. The previous study shows that most antenatal women had low and fair practices towards GDM.

\subsection{Methodology}

\subsection{Study design, study setting, and population}

This study was a cross-sectional survey done in selected public community health clinics in the Gombak area. In the district of Gombak, it has ten community health clinics with Maternal Child Health $(\mathrm{MCH})$ unit, which provides service to pregnant women. The target population in this study were pregnant women with GDM who came into the $\mathrm{MCH}$ unit for their antenatal appointment from $2^{\text {nd }} \mathrm{April} 2019$ until $30^{\text {th }}$ April 2019.

\subsection{Sampling method and sample}

The sampling method used in this study was a cluster proportionate random sampling method where only six clinics were chosen as Gombak district was divided into six zones to make sure that all clinics could be covered and the findings from this study can be representative of the whole population of Gombak district. Therefore, 1475 antenatal women with GDM from six selected clinics under 
Gombak Health District were the total population of this study. Out of that, 366 women needed to become respondents, with the distribution of each clinic being based on their total antenatal women with GDM, which later make up to $100 \%$ of the sample needed.

Sample in this study was selected according to the inclusion criteria, which were an antenatal woman with GDM, multigravida, age more than 18 years old and willing to participate in the study meanwhile the exclusion criteria were primigravida, pseudo-primigravida, antenatal women with pre-existing Type 2 Diabetes Mellitus and illiterate in Malay or and English. Table 1 summarizes the distribution of sample size according to selected clinics.

Table 1: Distribution of sample size according to selected clinics

\begin{tabular}{|l|c|c|c|}
\hline \multicolumn{1}{|c|}{ Public Health Clinic } & $\begin{array}{c}\text { Total Number of GDM } \\
\text { Clients per Year }\end{array}$ & $\begin{array}{c}\text { Proportionate Sample } \\
\text { (Percentage from total } \\
\text { population })\end{array}$ & $\begin{array}{c}\text { Sample Needed } \\
(\% \times 366)\end{array}$ \\
\hline Gombak Setia & 314 & $\frac{314}{1475} \times 100 \%=21.3 \%$ & 78 \\
\hline AU2 & 204 & $\frac{204}{1475} \quad \times 100 \%=13.8 \%$ & 113 \\
\hline Selayang Baru & 454 & $\frac{454}{1475} \times 100 \%=30.9 \%$ & 33 \\
\hline Taman Ehsan & 136 & $\frac{136}{1475} \quad \times 100 \%=9.2 \%$ & 41 \\
\hline Hulu Kelang & 166 & $\frac{166}{1475} \quad \times 100 \%=11.3 \%$ & 50 \\
\hline Kuang & 201 & $\frac{201}{1475} \quad \times 100 \%=13.7 \%$ & 366 \\
\hline Total & & \multicolumn{2}{|}{} \\
\hline
\end{tabular}

\subsection{Research instruments}

A self-administered questionnaire was used in this study, and it was provided in bilingual English and Malay. The questionnaire was derived based on a previous study by Herath et al. (2017) and Bhavadharini et al. (2017). The written permission to use the instrument was granted via email from the author. The detail of the instrument had been modified and adjusted according to the culture and belief of the Malaysian context, and one independent translator did the forward translation with a background of medical and one independent translator for back-translation. The questionnaire consisted of 36 questions and was divided into four sections.

Section A focused on social demographic data, which comprises six questions focused on age, ethnic group, marital status, level of education, occupation, and history of GDM in the previous pregnancy. Section B focused on knowledge towards GDM which consisted of ten dichotomous choices of questions with yes and no answers. Eight questions are positive statement questions while another two are negative statement questions. Every question with the right answer gets 1 mark and the maximum mark is 10 marks. The highest score indicates that the participants had higher knowledge of GDM. Section C focused on attitude towards GDM, consisting of 10 questions with Likert scale choice of answer with strongly disagree, disagree, undecided, agree, and strongly agree answer. This section comprises eight positive statements and two negative statements. For a positive statement, each strongly agree answer gets five marks, followed by four marks for agree, three marks for undecided, two marks for disagree, and one for strongly disagree.

Meanwhile, for negative statements, the marks given were vice versa from positive statements. Maximum marks for attitude towards GDM was 50 marks. Meanwhile, the minimum marks was ten marks. Section D focused on practice towards GDM. It comprises ten closedended questions with multiple choices of answer which are never, sometimes, and frequent. In this section, seven questions were positive statements while others were negative. For the answer of positive statements, participants who answer frequently get three marks, answer sometimes get two marks, and for answers never get one mark meanwhile, for negative statements, the marks were vice versa from positive statements. Therefore, highest marks in this section were 30 marks and lowest marks were ten marks.

\subsection{Reliability and validity}

Validity of the instruments had been sought from 6 experts of panels. Content validity index was calculated based on the translation equivalence, relevance, and clarity with the rating description from one to four. Most of the items had been rated between three and four by the panels showing relevant and clear items. Reliability for the instrument was done with the Cronbach Coefficient Alpha test as most of the questions used a scaled item with a value of 0.714 , and a pilot study was conducted to $10 \%$ of the total respondents who met the inclusion criteria at the setting area, which was 40 respondents as to test the study instrument.

\subsection{Data collection}

Data collection was done with the help of a data collector who was the nurse in charge of respondents. The researcher was at the study area every day and respondents who met the inclusion criteria randomly selected at the study setting area. First, the researcher approached the respondents to participate in the study, and who were willing to participate, the consent form was given prior to answering the questionnaire. Next, the researcher gave a set of self-administered questionnaires for respondents to answer, and it took about 15 to 
20 minutes to answer. The respondents were also instructed to enclose it in the envelope provided and then put it in the box that the researcher prepared to maintain confidentiality.

\subsection{Data analysis}

Data were analyzed using Statistical Package for Social Science (SPSS) version 23, and coding was assigned to each variable in the questionnaire accordingly. All data was sorted, organized, and arranged according to the identification number, which was tagged at the left upper side of each set of questionnaires and was done to avoid double entering of the data and more accessible to make a quick reference if needed.

Descriptive analysis was done for the frequency, percentage, mean and standard deviation for age, ethnicity, marital status, academic qualification, occupation, and history of GDM. In addition, a Spearman Rho test was used to answer research questions regarding the association between knowledge and attitude, knowledge and practice and attitude with practice among antenatal women with GDM. Logistic regression was used to answer the research question in predicting probability between the level of practice with a level of knowledge and level of attitude as the level of practice of GDM was the independent variable.

\subsection{Findings}

\subsection{Demographic characteristics}

The mean age for respondents was $31.94 \pm 4.88$ years with the maximum age, and the minimum age of respondents was 45 years old and 22 years old respectively, and more than half of the total respondents, which represented $71.8 \%$, were between the age group of below 35 years old. Malay ethnicity was the highest $84.4 \%$ followed by Indian $6.4 \%$, Chinese ethnicity $5.2 \%$ and $3.6 \%$ were from other ethnicities. $99.2 \%$ of total respondents were married women in this study. Findings in this study also showed that more than half of respondents had higher educational level which started from Diploma level to Doctor of Philosophy (Ph.D.), which indicates $56.3 \%$ and $36.2 \%$ of total respondents worked in the private sector, housewives $35.6 \%$, $22.4 \%$ worked as a government servant, and only $5.5 \%$ had owned a business. Table 2 summarizes the demographic characteristics of respondents in this study.

Table 2: Demographic characteristics of respondents participating in the study

\begin{tabular}{lll}
\hline Variable & Frequency (\%) & Mean \pm SD \\
\hline Age Group & & \\
$<35$ years & $260(71.8)$ & $(31.94,4.88)$ \\
$\geq 35$ years & $102(28.2)$ & \\
Ethnicity & \\
Malay & $307(84.4)$ \\
Chinese & $19(5.2)$ \\
Indian & $23(6.4)$ \\
Others & $13(3.6)$ \\
Marital Status & \\
Single & \\
Married & $3(0.8)$ \\
& $359(99.2)$ \\
Highest education level & \\
Primary Education & \\
Secondary Education & $6(1.6)$ \\
Tertiary Education & $156(42)$ \\
Occupation & $204(56.3)$ \\
Unemployed & \\
Employed & $130(35.9)$ \\
Owned Business & $212(58.6)$ \\
History of GDM & $20(5.5)$ \\
Yes & \\
No & \\
& & \\
& &
\end{tabular}


4.2 To determine the association between level of knowledge and level of attitude, level of knowledge with a level of practice, and level of attitude with the level of practice on GDM among antenatal women

Spearman Rho was used to analyzing the association between level of knowledge with a level of attitude, level of knowledge with a level of practice, and level of attitude with the level of practice. The finding of the study showed that there is an association between level of knowledge with a level of attitude with a $p$-value of less than 0.01 thus rejecting the null hypothesis meanwhile for the level of knowledge with a level of practice and level of attitude with the level of practice, the $p$-value was $>0.05$, therefore, the null hypothesis was accepted. The study also found that there is a positive relationship between the level of attitude with the level of practice and level of knowledge with a level of practice but it only had a strong relationship between the level of practice and level of attitude. Table 3 summarized the findings.

Table 3: Relationship between the level of knowledge with a level of attitude, level of knowledge with level of practice, level of attitude with the level of practice on GDM

\begin{tabular}{|l|c|c|}
\hline \multicolumn{1}{|c|}{ Variable } & Correlation coefficient & $p$-value* \\
\hline Knowledge-attitude & 0.312 & $<0.01$ \\
\hline Knowledge-practice & 0.069 & 0.191 \\
\hline Attitude-practice & 0.064 & 0.226 \\
\hline
\end{tabular}

${ }^{*}$ Correlation significant at 0.01 level (2 tailed)

\subsection{To identify predicting probability between the level of practice with a level of knowledge and level of attitude on GDM among antenatal women}

Logistic regression was used to determine the prediction for the probability of practice among respondents whether it has an association between level of knowledge and level of attitude of the respondents. This study had found that a one-point increase in knowledge of respondents corresponded to an increase in the practice of 0.059 meanwhile in a one-point increase in attitude was corresponded to an increase to 0.088 in practice. For level of knowledge, the standard error for unstandardized beta (SE B) was 0.060 for the level of knowledge and 0.051 for the level of attitude which indicates that there is a significant level of knowledge and attitude with the level of practice.

\subsection{Discussion}

This was the first study done in Malaysia related to KAP of GDM where most of the previous study was only focused on Type 2 Diabetes but only 1 study had done by Universiti Sains Malaysia (USM) on exploring the knowledge rather than attitude and practice. This study was done to explore the association between knowledge, attitude, and practice among antenatal women regarding GDM. Findings from this study showed that, only knowledge had a significant association between attitudes where the $p$-value is less than 0.05 thus rejecting the null hypothesis. Yizukanji and Mwanakasale (2018) with their study aim to establish awareness, level of knowledge, attitude, and practice among pregnant women attending antenatal care had found similarities with these study findings where findings showed that knowledge and attitude are able to indicate good practice towards GDM. However, even though the knowledge is there, but the attitude and practice were still not so good.

In order to predict the practice of pregnant women towards GDM based on her level of knowledge and attitude, logistic regression analysis was done and found that an increase in one point of knowledge will increase about half of practice and an increase one point of an attitude will increase about 0.08 in practice. This shows that a person's level of knowledge plays an important role in changing an individual's attitude and practices on their health literacy. These findings were in contrast with Ge et.al (2016) in their qualitative exploratory study to explore beliefs about health and illness and health-related behavior among urban Chinese women with GDM in a Chinese socio-cultural context had found that the beliefs and health-related behavior were influenced by Chinese culture, which can sometimes but not always reduce the effect of the disease.

After conducting this study, as to the researcher's knowledge, this study is the only study found related to knowledge, attitude, and practice (KAP) on GDM done in Malaysia and this was the limitation found in this study. This is because many studies were found in exploring knowledge, attitude, and practice related to type 2 Diabetes Mellitus. Only one study had been done in Malaysia before by Hussain et.al in 2015 but only explored the association between attitude and treatment with glycaemic level to antenatal women with GDM. Therefore, the researcher was unable to compare in-depth this study's findings with a similar study.

\subsection{Conclusion and Recommendations}

Some recommendations were made following this study. In order to increase and enhance awareness on GDM among antenatal women, comprehensive health education with health promotion programs need to be done on a large scale and to make sure that the health education is not only given to the antenatal women only but to their husband or partner as well. This is because the partner will have knowledge on GDM thus together with antenatal women in preventing complications following GDM and becoming type 2 Diabetes Mellitus. Since there is limited research related to KAP of GDM in Malaysia, researchers found that the need for more research findings in this area might help the nursing area in improving the technique of giving health education or maybe using mass media in giving health education as the following globalization. 


\section{Acknowledgment}

This research was self-funded by authors. We wish to gratefully acknowledge the Jabatan Kesihatan Negeri Selangor (JKNS) and Gombak Health District for allowing us to do this study in their area, to the nurses as being data collectors and to the antenatal women who participated in this study.

\section{References}

Adznam,S.N.H., Sedek,R., \& Kasim,Z.M.(2018). Assessment of Knowledge, Attitude and Practice Levels Regarding Anaemia Among Pregnant Women in Putrajaya, Malaysia. Pakistan Journal of Nutrition, 17: 578-585. Retrieved online from https://scialert.net/fulltext/?doi=pjn.2018.578.585\&org=11

American Diabetes Association, (2014), "Diagnosis and classification of Diabetes Mellitus", Diabetes Care, Vol 37, Supplement 1, page S81-S90. Retrieved online from https://doi.org/10.2337/dc14-S081

Bhavadharini,B.,Deepa,M.,Nallaperumal,S.,Anjana,R.M.,\&Mohan,V.(2017). Knowledge about gestational diabetes mellitus amongst pregnant women in South Tamil Nadu. Journal of Diabetology,8(1):22-26. Retrieved online from https://doi.10.4103/jod.jod_2_17

Bhowmik,B.,Afsana,F.,Ahmed,T.,Siddiquee,T.,Ahmed,T.,Pathan,F.,Mahtab,H.,\&Khan,A.K.A.(2018). Evaluation of knowledge regarding Gestational Diabetes Mellitus : A Bangladeshi study, Public Health Journal, Vol 161,67-74,Elsevier. Retrieved online from https://doi.org/10.1016/j.puhe.2018.04.017

Carolan, M., Steele, C., \& Margetts, H. (2010). Knowledge of gestational diabetes among a multi-ethnic cohort in Australia. Midwifery, 26(6), 579-588. https://doi.org/10.1016/j.midw.2009.01.006

Ge,L.,Albin,B.,Hadziabdic,E.,Hjelm,K.,\&Rask,M.(2016). Beliefs about health and illness and health-related behaviour among urban women with gestational diabetes mellitus in the south east of China. Journal of Transcultural Nursing,27(6),593-602. Retrieved online from https://doi.org/10.1177/1043659615594677

Gombak Health District, Monthly Census of Antenatal Booking \& Monthly Census of Prevalence of GDM

Herath, H., Herath, R., \& Wickremasinghe, R. (2017). Gestational diabetes mellitus and risk of type 2 diabetes 10 years after the index pregnancy in Sri Lankan women-A community-based retrospective cohort study. PloS one, 12(6), e0179647. Retrieved online from https://doi.org/10.1371/journal.pone.0179647

Herath, H. M. M., Weerasinghe, N. P., Dias, H., \& Weerarathna, T. P. (2017). Knowledge, attitude and practice related to diabetes mellitus among the general public in Galle district in Southern Sri Lanka: a pilot study. BMC Public Health, 17(1). Retrieved online from https://doi.org/10.1186/s12889-017-4459-5

Hussain,Z., Yusoff, Z. M., \& Sulaiman, S. A. S. (2015). A study exploring the association of attitude and treatment satisfaction with glycaemic level among gestational diabetes mellitus patients. Primary Care Diabetes. https://doi.org/10.1016/j.pcd.2014.10.002

International Diabetic Federation. Diabetic atlas (6 $\left.6^{\text {th }} \mathrm{ed}\right)$. (2016). Retrieved online from www.idf.org/diabetesatlas

Islam, B., Islam, F., Abu, M., Nyeem, B., Mannan, A., \& Neaz, A. N. A. (2017). Knowledge and attitude regarding gestational diabetes mellitus ( GDM ) among obese pregnant women coming for an antenatal checkup at a tertiary care hospital. Indian Journal of Chemical Studies, Vol 5(5):179-189. Retrieved online from https://www.researchgate.net/publication/321213494

Jeganathan,R.,\& Karalasingam,S.D.(2012).National Obstetrics Registry Report : 3 ${ }^{\text {rd }}$ Report of National Obstetrics Registry 2011-2012.Malaysia. National Obstetrics Registry and the Clinical Research Centre (CRC), Ministry of Health Malaysia. Retrieved online from http://www.acrm.org.my/nor/doc/reports/NOR_REPORT_2012.pdf

Koo,H.C.,Poh,B.K.,\&Ruzita,A.T.(2015). Assessment of Knowledge, Attitude and Practice Towards Whole Grains International Journal of Food Science , Nutrition and Dietetics ( IJFS ) ISSN 2326-3350 Retrieved online from https://doi.org/10.19070/2326-3350-1500032

Logakodie, S., Azahadi, O., Fuziah, P., Bib, N., Sf, T., Zzr, Z.,Mimi, O. (2017). Gestational diabetes mellitus : The prevalence , associated factors and foeto-maternal outcome of women attending antenatal care. Malaysian Family Physician, 12(2), 9-17. Retrieved from https://www.ncbi.nlm.nih.gov/pmc/articles/PMC5802775/pdf/MFP12-09.pdf

Muche, A.A., Olayemi, O.O. \& Gete, Y.K. (2019). Prevalence of gestational diabetes mellitus and associated factors among women attending antenatal care at Gondar town public health facilities, Northwest Ethiopia. BMC Pregnancy Childbirth 19, 334. Retrieved online from https://doi.org/10.1186/s12884-019-2492-3

Ogu, R. N., Maduka, O., Agala, V., Alamina, F., Adebiyi, O., Edewor, U. \& Abam, C. (2019). Gestational Diabetes Mellitus Knowledge Among Women of Reproductive Age in Southern Nigeria: Implications for Diabetes Education. International Quarterly of Community Health Education. Retrieved online from https://doi:10.1177/0272684x19876526

Shriraam.V., Rani,S.M., Sathiyasekaran,B., \& Mahadevan,S. (2013).Awareness of gestational diabetes mellitus among antenatal women in a primary health center in South India. Indian Journal of Endocrinology and Metabolism, Vol 17(1):146-148. Retrieved online from https://doi.org/10.4103/2230-8210.107861

Utz, B., Assarag, B., Essolbi, A., Barkat, A., Delamou, A., \& De Brouwere, V. (2017). Knowledge and practice related to gestational diabetes among primary health care providers in Morocco: Potential for defragmentation of care? Primary Care Diabetes, 11(4), 389-396. http://dx.doi:10.1016/j.pcd.2017.04.005

World Health Organization. (2016).Global reports on Diabetes. Retrieved online from https://www.who.int/diabetes/global-report/en/

World Health Organization (2017). Diabetes fact sheet. Retrieved online from https://www.who.int/mediacentre/factsheets/fs311/en/

Yizukanji, S., \& Mwanakasale, V. (2018). Knowledge, Attitude and Practices among Women Attending Antenatal Clinic towards Gestational Diabetes Mellitus in Mufulira Town, Zambia, 1(7), 1-8. Retrieved online from

www.ijciar.com/pdfcopy/2018/nov2018/ijciar-01.pdf 